\title{
Volumetric Analysis of Cranial Vault Distraction for Cephalocranial Disproportion ${ }^{1}$
}

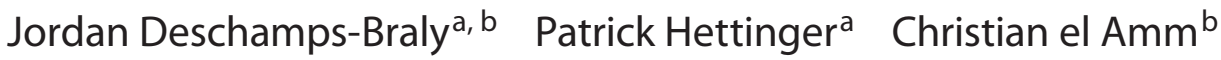 \\ Arlen D. Denny ${ }^{\mathrm{a}}$ \\ ${ }^{a}$ Medical College of Wisconsin, Children's Hospital of Wisconsin, Milwaukee, Wisc., and bivision of Plastic Surgery, \\ The University of Oklahoma College of Medicine, Oklahoma City, Okla., USA
}

\section{Key Words}

Volumetric analysis - Cranial vault distraction • Ventricle •

Cerebral perfusion $\cdot$ Finite element

\begin{abstract}
The purpose of this study was to provide an objective analysis and quantify the intracranial volume change produced by cranial vault distraction osteogenesis. We recently published a technique to expand the cranial vault by distraction in symptomatic patients with findings of cephalocranial disproportion. Resolution of symptoms was documented in that publication. In this current study, we analyzed postdistraction intracranial volume changes in 11 consecutive patients retrospectively from $10 / 2001$ to $11 / 2010$ with institutional review board approval. These 11 patients were treated by cranial vault distraction osteogenesis for symptomatic cephalocranial disproportion. Pre- and postoperative CT DICOM data were analyzed using specialized software to generate finite element models. Intracranial and ventricular volumes were calculated. Topographical surface maps were generated to document and quantify areas of change. Possible effects on brain physiology are discussed. Pre- and postoperative CT scans were obtained at an average of 3.5 months prior to, and 4.2 months following distraction, respectively. Average age at distraction was 55.72 months (range 26-104 months). Operative time averaged $2 \mathrm{~h} 44 \mathrm{~min}$
\end{abstract}

(range 127-198 $\mathrm{min}, \mathrm{SD}=30.6$ ). Intracranial and ventricular volumes increased by an average of 77.01 and $4.85 \mathrm{ml}$, respectively. Nonventricular intracranial volumes increased by $5.91 \%, 71.67 \mathrm{ml}$ following distraction. All postoperative volume changes were statistically significant ( $p \leq 0.000025$ ). The ability to use the same methodology to quantify ventricular volume changes was unexpected. The fact that all ventricles expanded after distraction at approximately $10 \%$ of the total intracranial volume increase indicates that compensatory mechanisms had been activated. We conclude that this occurs at the expense of cerebral blood flow.

Copyright $\odot 2012$ S. Karger AG, Basel

\section{Background}

Cephalocranial disproportion is a term to describe an imbalance between cranial vault size and brain volume. Children with craniosynostosis develop growth restrictions of the skull and may ultimately become symptomatic. In a few cases, children may show signs of recurrent cephalocranial disproportion years after appropriate initial treatment for premature suture fusion. Symptomatic

\footnotetext{
Presented at the International Society of Craniofacial Surgery, XIV Biennial International Congress, Victoria Falls, Zambia, August 15, 2011
}

\section{KARGER}

Fax +41613061234 E-Mail karger@karger.ch www.karger.com
(C) 2012 S. Karger AG, Basel $1016-2291 / 11 / 0476-0396 \$ 38.00 / 0$

Accessible online at: www.karger.com/pne
Arlen D. Denny, MD, FACS, FAAP

Medical College of Wisconsin, Children's Hospital of Wisconsin

$9000 \mathrm{~W}$ Wisconsin Ave C340

Milwaukee, WI 53201 (USA)

Tel. +1 414266 2825, E-Mail adenny@ CHW.org 
Fig. 1. Preoperative (a, c) and postoperative (b, d) CT scans of internal distraction osteogenesis for cephalocranial disproportion. Note: Differential expansion of the posterior parietal bones.
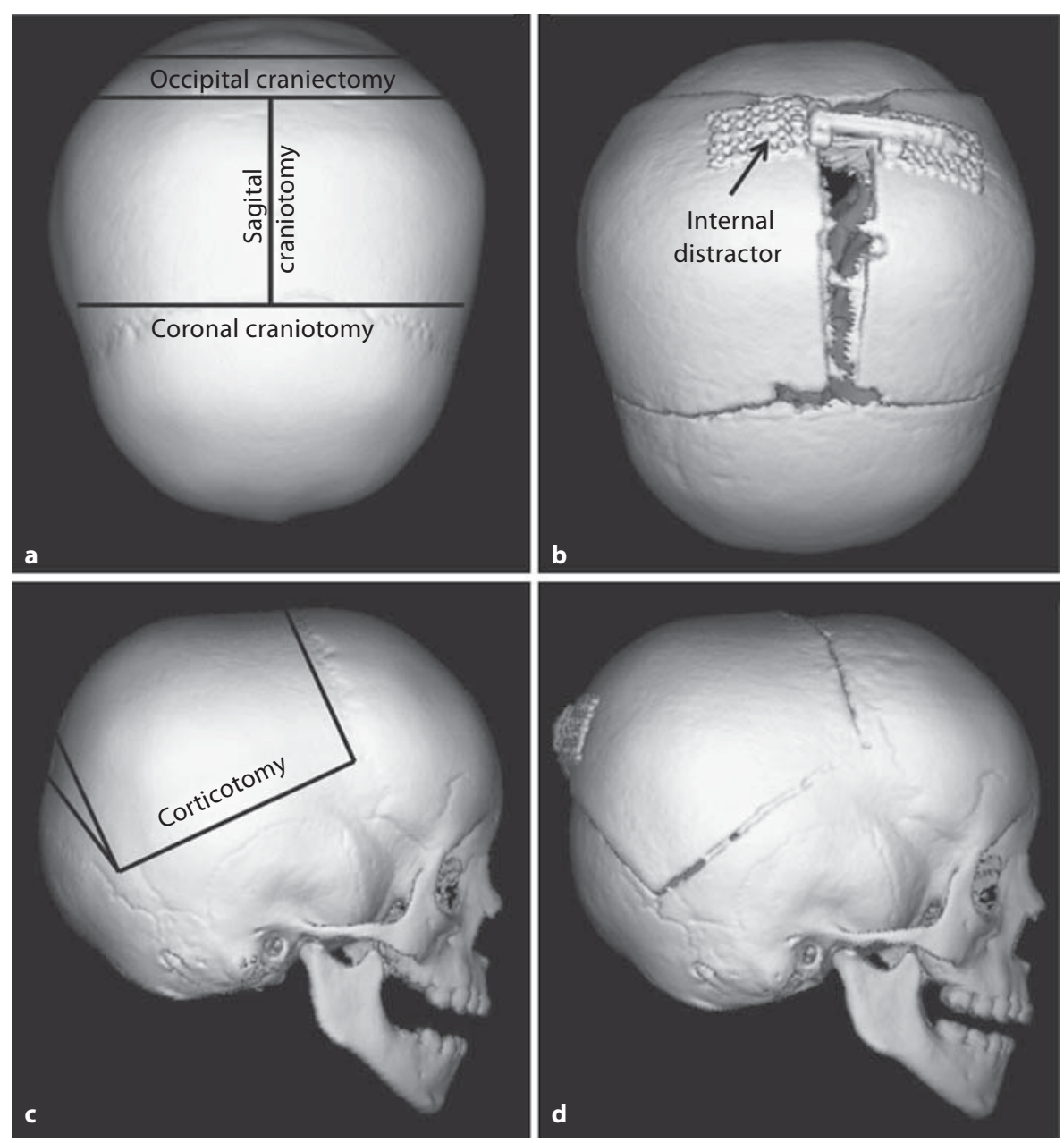

cephalocranial disproportion suggests insufficient room for intracranial contents to behave in a normal physiologic manner. Three of 11 patients had documented elevated intracranial pressure (ICP). These children are often treated by traditional cranial vault remodeling. Distraction osteogenesis of the cranial vault has been shown to relieve increased ICP and appears to remove the pathophysiologic intrusion upon normal brain function.

Ilizarov and Soibel'man [1] developed the technique and science of distraction osteogenesis. They applied the technique to lengthen long bones that ossify by endochondral replacement. Since the original report in orthopedic literature, applications for distraction have broadened to include the entire craniofacial skeleton [2-4].

A number of reports of successful distraction osteogenesis of membranous bones of the cranial vault have been published. Recently, a technique for cranial vault volume expansion by distraction to correct cephalocra- nial disproportion has been published (fig. 1) [5]. This technique was devised as a safe and reliable method to correct cephalocranial disproportion resulting from premature sagittal suture fusion.

The goal of distraction for symptomatic patients is to increase the amount of intracranial volume for the physiologically active brain parenchyma and its vascular supply. The ventricular system acts as a volume buffer and provides capacitance in response to changes in intracranial volume. Knowing the extent of ventricular volume changes after cranial vault distraction is important to understanding the dynamics of intracranial physiology. The effect of intracranial volume expansion on the size of the ventricles will be discussed. Without assessing the ventricular system volume changes, it is not possible to determine whether expansion of the intracranial space causes a meaningful increase in the other two intracranial compartments: brain parenchyma and vascular vol- 
Table 1. Intracranial volume changes before and after distraction

\begin{tabular}{llllll}
\hline Patient & Diagnosis & $\begin{array}{l}\text { Age at time of dis- } \\
\text { traction, months }\end{array}$ & $\begin{array}{l}\text { Preoperative intra- } \\
\text { cranial volume, ml }\end{array}$ & $\begin{array}{l}\text { Postoperative intra- } \\
\text { cranial volume, ml }\end{array}$ & $\begin{array}{l}\text { Change in } \\
\text { volume, ml }\end{array}$ \\
\hline 1 & sagittal synostosis & 62 & $1,315.60$ & $1,387.00$ & 71.40 \\
2 & sagittal, B/L lambdoid & 33 & $1,212.10$ & $1,304.50$ & 92.40 \\
3 & sagittal, B/L lambdoid & 82 & $1,192.20$ & $1,237.90$ & 45.70 \\
4 & sagittal synostosis & 53 & $1,364.00$ & $1,445.00$ & 81.00 \\
5 & sagittal synostosis & 47 & $1,235.00$ & $1,302.00$ & 67.00 \\
6 & sagittal synostosis & 76 & $1,478.70$ & $1,567.30$ & 88.60 \\
7 & sagittal synostosis & 48 & 710.26 & 741.80 & 31.54 \\
8 & sagittal synostosis & 104 & $1,463.80$ & $1,559.40$ & 95.60 \\
9 & sagittal synostosis & 27 & $1,207.51$ & $1,327.38$ & 119.87 \\
10 & sagittal synostosis & 55 & $1,319.56$ & $1,368.46$ & 48.90 \\
11 & sagittal synostosis & 26 & $1,055.45$ & $1,155.11$ & 99.66 \\
\hline Average & 58.8 & $1,232.20$ & $1,308.71$ & 77.01 \\
\hline
\end{tabular}

Table 2. Ventricular volume changes before and after distraction

\begin{tabular}{llclr}
\hline Patient & Diagnosis & $\begin{array}{l}\text { Preoperative ven- } \\
\text { tricular volume, } \mathrm{ml}\end{array}$ & $\begin{array}{l}\text { Postoperative ven- } \\
\text { tricular volume, ml }\end{array}$ & $\begin{array}{l}\text { Ventricular vol- } \\
\text { ume change, } \%\end{array}$ \\
\hline 1 & sagittal synostosis & 22.82 & 22.86 & 0.20 \\
2 & sagittal, B/L lambdoid & 28.02 & 29.58 & 5.00 \\
3 & sagittal, B/L lambdoid & 9.61 & 15.06 & 56.00 \\
4 & sagittal synostosis & 16.41 & 25.70 & 57.00 \\
5 & sagittal synostosis & 6.15 & 9.36 & 52.00 \\
6 & sagittal synostosis & 15.27 & 19.63 & 28.50 \\
7 & sagittal synostosis & 5.86 & 8.51 & 46.00 \\
8 & sagittal synostosis & 17.36 & 29.28 & 68.00 \\
9 & sagittal synostosis & 15.85 & 21.40 & 35.02 \\
10 & sagittal synostosis & 14.97 & 18.92 & 26.38 \\
11 & sagittal synostosis & 17.00 & 22.30 & 31.17 \\
\hline Average & & 15.39 & 20.24 & 36.84 \\
\hline
\end{tabular}

ume. Using mathematically generated finite element models and sophisticated segmentation tools, we demonstrate that these two compartments increase in volume differentially after cranial vault distraction.

\section{Methods}

Approval from the Children's Hospital of Wisconsin Institutional Review Board for this study was obtained prior to initiating data collection. Eleven consecutive cases of cranial vault expansion using transverse asymmetric distraction osteogenesis were retrospectively reviewed from 10/2001 to $11 / 2010$. Three-dimensional pre- and postoperative CT DICOM (Digital Imaging and Communications in Medicine) data were then analyzed using Amira ${ }^{\circledR}$ software (Visage Imaging, San Diego, Calif., USA). We calculated both intracranial and ventricular volumes (tables 1, 2). Two patients with incomplete postoperative CT scan data were excluded from this study. Operative indication, estimated blood loss, operative time, and postoperative complications are noted. Relief of symptoms was also documented.

Accurate analysis of irregular three-dimensional structures and their contained volumes is now possible. Borrowing from established engineering techniques, we constructed finite element models which are a series of triangles assembled into a mesh. This converts the analysis of complex surfaces into a series of linear equations. Accuracy increases in proportion to the density of the mesh. For this study, each CT scan was divided into over 2 million triangles, or finite elements (fig. 2). Surface mesh maps were generated from each patient's CT DICOM data using high-powered graphics processing. These data were then used to calculate the total volume of the intracranial space and the ventricles separately, before and after distraction of the cranial vault. 
Fig. 2. View of high-density mesh framework with close-up of the surface.

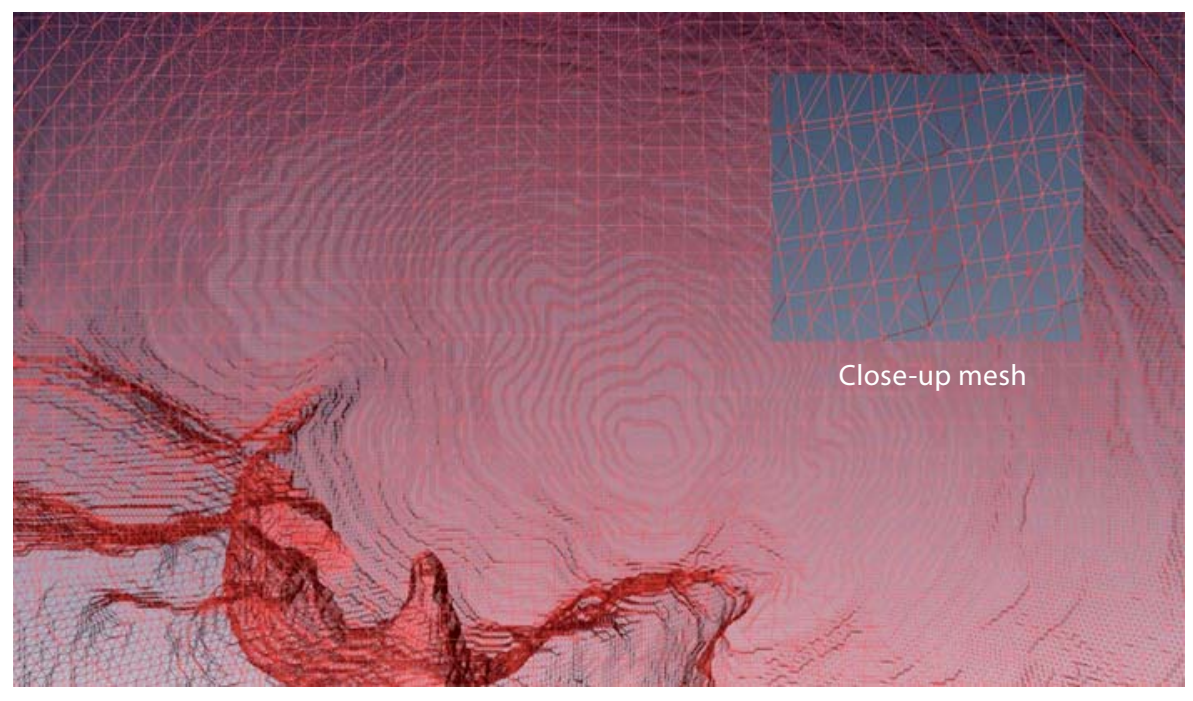

The intracranial space was segmented from the surrounding bone using variations in tissue density expressed as Hounsfield units. The ventricles were separated from the parenchyma using the same technique. Cranial defects and foramina were manually closed. We calculated the volume of the combined brain parenchyma and vascular space by subtracting the ventricular reservoir from the intracranial volume (fig. 3-5). Paired Student's t test was performed on pre- and postoperative measurements.

Topographic mapping provides a visual tool which depicts three-dimensional changes between pre- and postdistraction intracranial mesh surface models which are mathematically accurate. This is accomplished by overlaying and precisely aligning these finite element models. The analysis aligns the models using a contour analysis algorithm which ensures that unchanged areas of the skull are precisely aligned. Then the software determines the linear change in surface distance between pre- and postdistraction using a mathematical algorithm called iterative closest point analysis. This process then calculates the distance between the millions of matched points on the two surface models and generates a color map. Each different color represents a specific postdistraction displacement of surface points away from the predistraction model. The surface changes correlate with underlying volume increases. These color maps provide a clear visual image to allow specific understanding of where and to what degree volume change has occurred.

\section{Surgical Technique}

The patient is prepped and draped in the prone position. A posterior scalp flap is raised through a standard bicoronal incision. A subperiosteal dissection is carried out from anterior to the coronal suture to posterior to the lambdoid sutures. A paramidline sagittal osteotomy is made from the coronal sutures to the lambdoid sutures. Vertical osteotomies are made parallel and posterior to the coronal, and anterior to the lambdoid sutures on each side. These osteotomies extend from parasagittal to near the skull base. A linear corticotomy is made along the base of the parietal bone flaps connecting the coronal and lambdoid osteotomies. This functions as a hinge just above the skull base and allows outward rotation of the parietal flaps. An osteosynthesis plate is placed across the parasagittal osteotomy slightly behind the coronal suture. This plate functions to preferentially create expansion in the posterior parietal region and preserve an aesthetic result in the temporal region.

To decrease the AP diameter in selected cases, a wedge may be removed along the lambdoid sutures with a horizontal wedge closing osteotomy at the base of the occipital bone flap. A corticotomy is made across the base of the occipital bone flap allowing the posterior bone flap to be flexed anteriorly to decrease the anterior-posterior diameter if needed [5].

An internal distractor is mounted across and perpendicular to the parasagittal osteotomy. The distractor may be placed at varying distances from front to back. The distractor placement controls the maximum distance of distraction at the lambdoid suture osteotomies and may be accurately predicted using standard lever equations. All distractors were activated $0.5-1.0 \mathrm{~mm} /$ day to a maximum of $20 \mathrm{~mm}$ at the device.A Stryker MIDS device was used in all patients.

\section{Results}

Thirteen cases underwent cranial vault distraction. Eleven patients had complete DICOM data sets from CT imaging studies. Nine patients had sagittal synostosis and 2 had pansynostosis. Symptomatic cephalocranial disproportion secondary to absent sagittal suture was the indication for operation in all patients. Symptoms included intractable headaches, behavioral disturbances, and vision changes. Three patients allowed ICP monitoring with Richmond screw prior to surgery. All were 


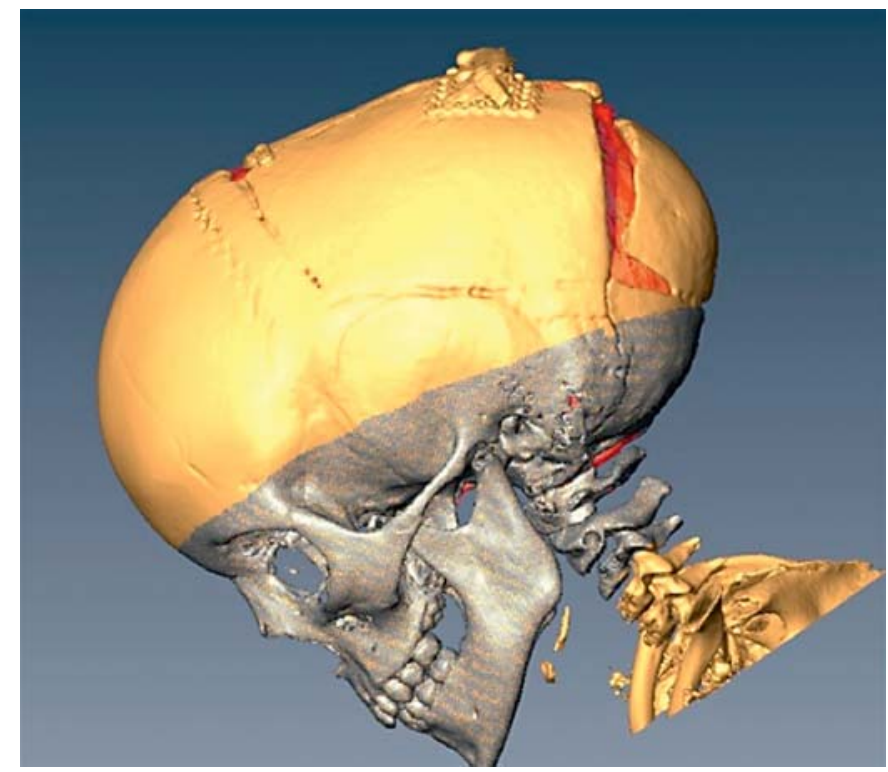

Fig. 3. Postdistraction skull model with yellow areas expected to undergo volume changes. Color refers to the online version only.

significantly elevated. Two patients had severely abnormal optic disk changes which resolved after distraction and remained normal more than 5 years later. Average age at the time of operation was 55.7 months (range 26104 months). Average operative time was $153.9 \mathrm{~min}$ (range 93-198 $\mathrm{min}$ ) with an average blood loss of 272.7 $\mathrm{ml}$ (range 50-400 ml).

Preoperative CT scans were performed an average of 3.5 months prior to distraction (range 1-7 months). Average preoperative intracranial volume was $1,232.2 \mathrm{ml}$ (range 710.3-1,478.7 ml) (table 1). Postoperative CT scans were performed an average of 4.2 months following distraction (range 1-13 months). Average postoperative intracranial volume was $1,308.7 \mathrm{ml}$ (range 741.8-1,567.3 $\mathrm{ml}$ ). Preoperative ventricular volume averaged $15.4 \mathrm{ml}$ (table 2), while postoperative ventricular volume averaged $20.2 \mathrm{ml}$ (table 2). Changes in pre- and postoperative intracranial and ventricular volumes were statistically significant ( $\mathrm{p}$ values of 0.006 and $<0.00002$, respectively). Preoperative nonventricular intracranial volume averaged 1,216.8 $\mathrm{ml}$ (range 704.4-1,463.4 ml), while postoperative nonventricular intracranial volume averaged $1,288.5 \mathrm{ml}$ (range 733.3-1,547.7 ml) (table 3). This equals an increase in nonventricular intracranial volume of $5.9 \%$. This increase adjusts to $4.5 \%$ when considering normal calvarial growth between pre- and postoperative CT scans (table 4).

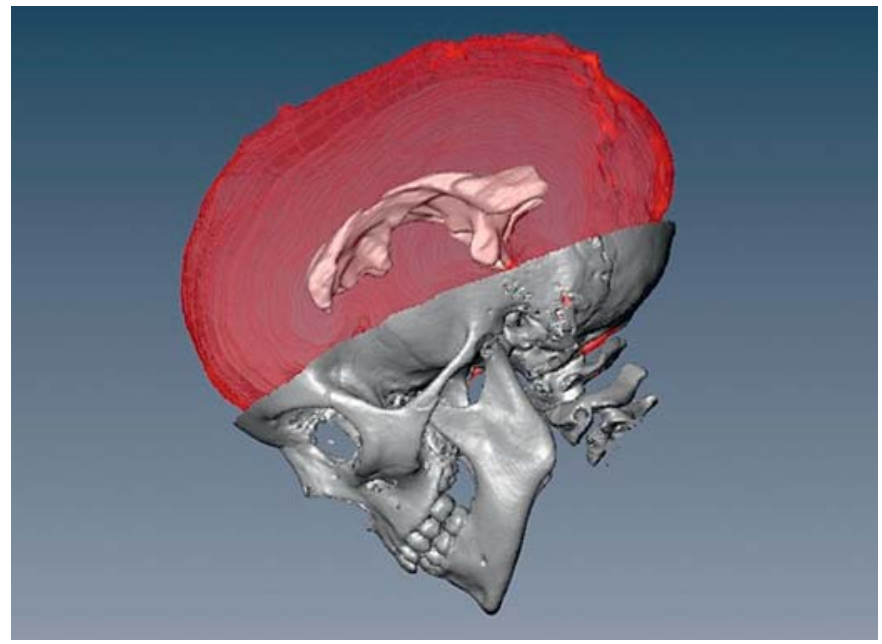

Fig. 4. Postdistraction with skull removed and intracranial space and ventricles demonstrated.

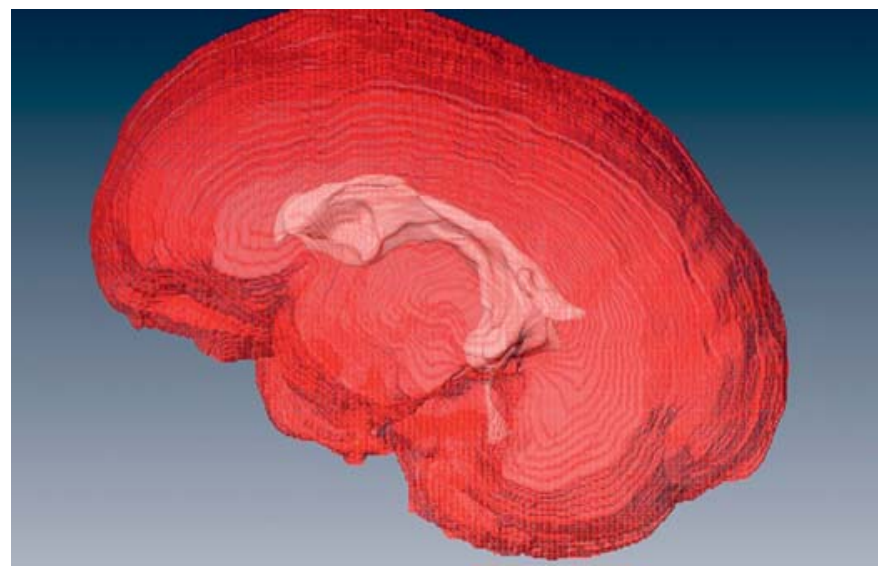

Fig. 5. Ventricle and intracranial compartment contours.

Only a small percentage of the increase in intracranial volume achieved by distraction is attributable to increased ventricular volume $(15.39 \mathrm{ml}$ preoperative vs. $20.24 \mathrm{ml}$ postoperative, $\mathrm{p}=0.00568$ ) (table 2 ). The percent increase in ventricle size is $36.84 \%$. Accounting for interval growth of the cranium and expansion of the ventricles, we demonstrate that the brain parenchyma and vascular space increased on average by $4.46 \%$ (table $4 ; 57.46$ $\mathrm{ml} ; \mathrm{p} \leq 0.00002)$. 
Table 3. Nonventricular intracranial volume changes before and after distraction

\begin{tabular}{lllll}
\hline Patient & Diagnosis & $\begin{array}{l}\text { Preoperative intracranial } \\
\text { compartment minus ventricular } \\
\text { volume, ml }\end{array}$ & $\begin{array}{l}\text { Postoperative intracranial } \\
\text { compartment minus ventricular } \\
\text { volume, ml }\end{array}$ & $\begin{array}{l}\text { Increase in } \\
\text { nonventricular } \\
\text { intracranial } \\
\text { volume, \% }\end{array}$ \\
\hline 1 & sagittal synostosis & $1,292.78$ & $1,364.14$ & 5.60 \\
2 & sagittal, B/L lambdoid & $1,184.08$ & $1,274.92$ & 7.70 \\
3 & sagittal, B/L lambdoid & $1,182.59$ & $1,222.85$ & 3.40 \\
4 & sagittal synostosis & $1,347.59$ & $1,419.30$ & 5.30 \\
5 & sagittal synostosis & $1,228.85$ & $1,292.64$ & 5.20 \\
6 & sagittal synostosis & $1,463.43$ & $1,547.67$ & 5.80 \\
7 & sagittal synostosis & 704.40 & 733.29 & 4.10 \\
8 & sagittal synostosis & $1,446.44$ & $1,530.12$ & 5.80 \\
9 & sagittal synostosis & $1,191.66$ & $1,305.98$ & 9.60 \\
10 & sagittal synostosis & $1,304.59$ & $1,349.54$ & 3.45 \\
11 & sagittal synostosis & $1,038.45$ & $1,132.81$ & 9.09 \\
\hline Average & & $1,216.81$ & $1,288.48$ & 5.91 \\
\hline
\end{tabular}

Table 4. Nonventricular intracranial volume changes accounting for growth before and after distraction

\begin{tabular}{llll}
\hline Patient & Diagnosis & $\begin{array}{l}\text { Normal growth between pre- } \\
\text { and postoperative CT scans, } \%\end{array}$ & $\begin{array}{l}\text { Increase in nonventricular intracranial } \\
\text { volume accounting for normal growth, \% }\end{array}$ \\
\hline 1 & sagittal synostosis & 0.90 & 4.70 \\
2 & sagittal, B/L lambdoid & 3.90 & 3.80 \\
3 & sagittal, B/L lambdoid & 0.20 & 3.20 \\
4 & sagittal synostosis & 0.10 & 5.20 \\
5 & sagittal synostosis & 2.20 & 3.00 \\
6 & sagittal synostosis & 0.20 & 5.60 \\
7 & sagittal synostosis & 0.20 & 3.90 \\
8 & sagittal synostosis & 0.20 & 5.60 \\
9 & sagittal synostosis & 1.10 & 8.50 \\
10 & sagittal synostosis & 3.00 & 0.45 \\
11 & sagittal synostosis & 4.00 & 5.09 \\
\hline Average & & 1.45 & 4.46 \\
\hline
\end{tabular}

Table 5. Results of ICP monitoring in 3 patients

\begin{tabular}{lllll}
\hline Patient & $\begin{array}{l}\text { Intracranial pressure } \\
\text { before distraction, mm Hg }\end{array}$ & $\begin{array}{l}\text { Intracranial pressure } \\
\text { after distraction, mm Hg }\end{array}$ & $\begin{array}{l}\text { Intracranial vol- } \\
\text { ume change, \% }\end{array}$ & $\begin{array}{l}\text { Intracranial pres- } \\
\text { sure change, \% }\end{array}$ \\
\hline 6 & 35 & 17 & 5.9 & 51.4 \\
7 & 30 & 5 & 4.4 & 83.3 \\
10 & 29 & 4 & 3.7 & 86.2 \\
\hline Average & 31.3 & 8.7 & 4.7 & 73.6 \\
\hline
\end{tabular}


Fig. 6. Color map showing changes in intracranial volume in a single patient.
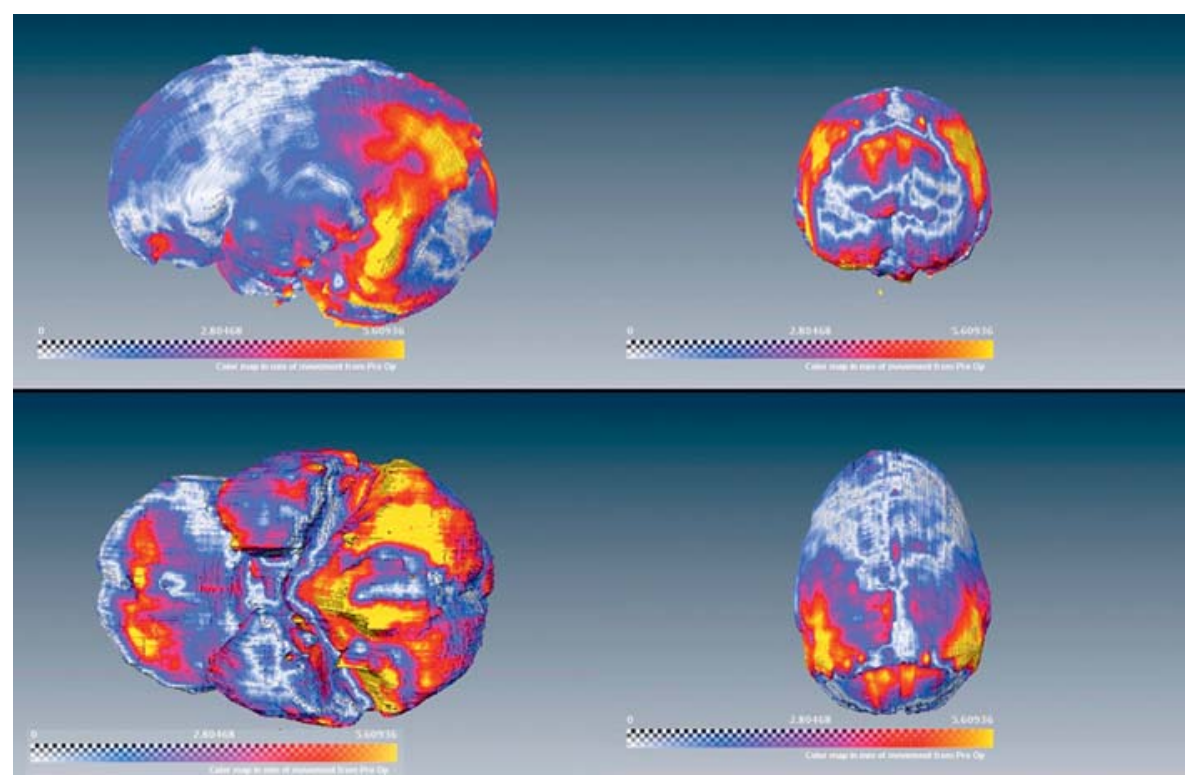

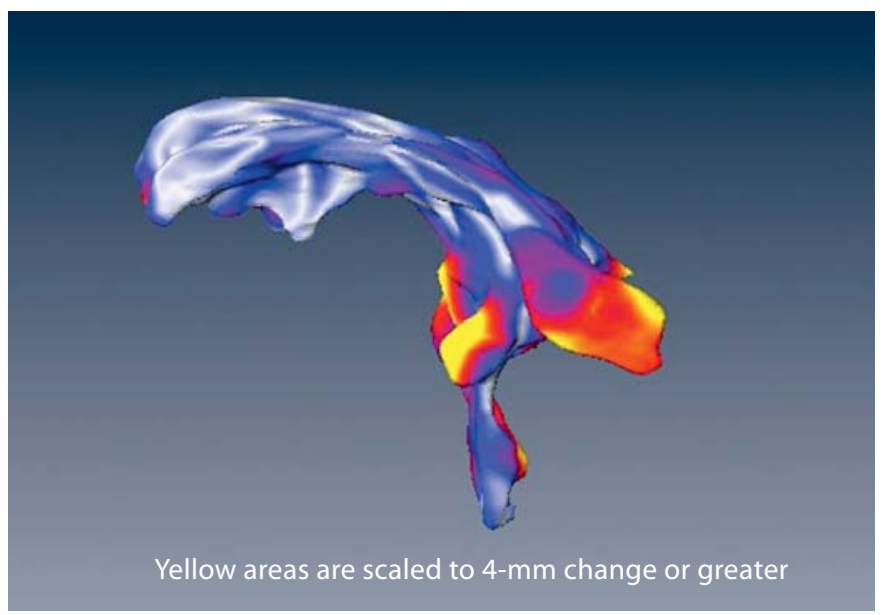

Fig. 7. Color map showing changes in ventricular volume. Yellow areas represent $4-\mathrm{mm}$ or greater change. Color refers to the online version only.

In 3 patients, we observed normalization of elevated ICP verified by invasive ICP monitors. Significant longterm improvement in clinical symptoms was also observed. The total intracranial volume changes and ventricular volume changes in those patients with corrected ICP were congruent with all other unmonitored patients. Despite these relatively small percent intracranial volume changes (4.46\% corrected average), it was sufficient to reduce ICP in monitored patients by more than $50 \%$ (table 5 ).

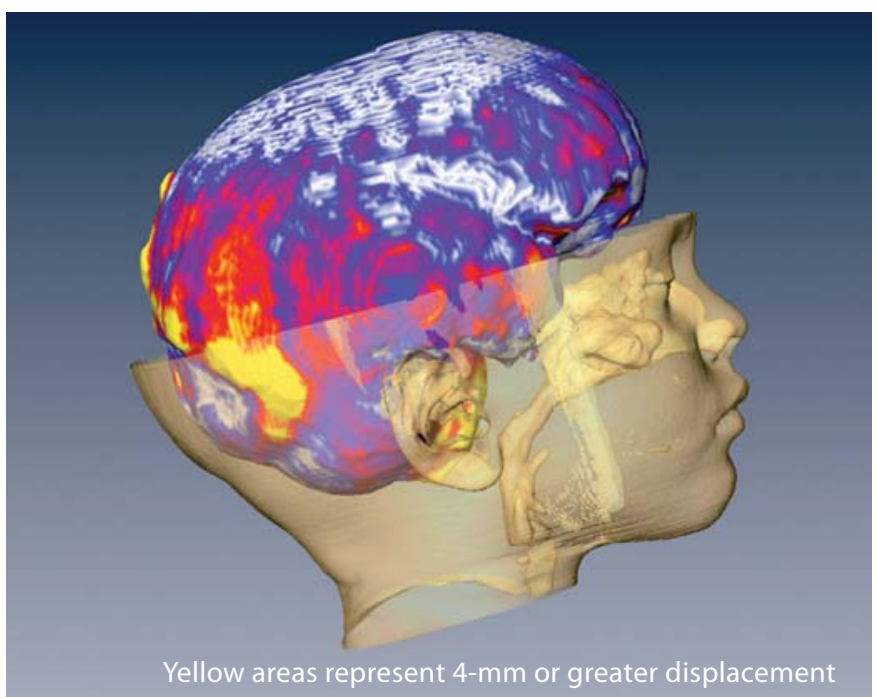

Fig. 8. Color map showing intracranial volume changes in situ. Color refers to the online version only.

Figures 6-9 are color maps that demonstrate graphically the volume changes in the intracranial space and ventricular spaces in 1 patient. These changes in volume predominantly occur in the posterior portions of the ventricle. Figure 10 depicts an additional patient with very similar changes. In both patients, areas of change are predominantly located in the posterior parietal regions. The skull base color map in figure 11 demonstrates an unexpected increase in volume in that area. 


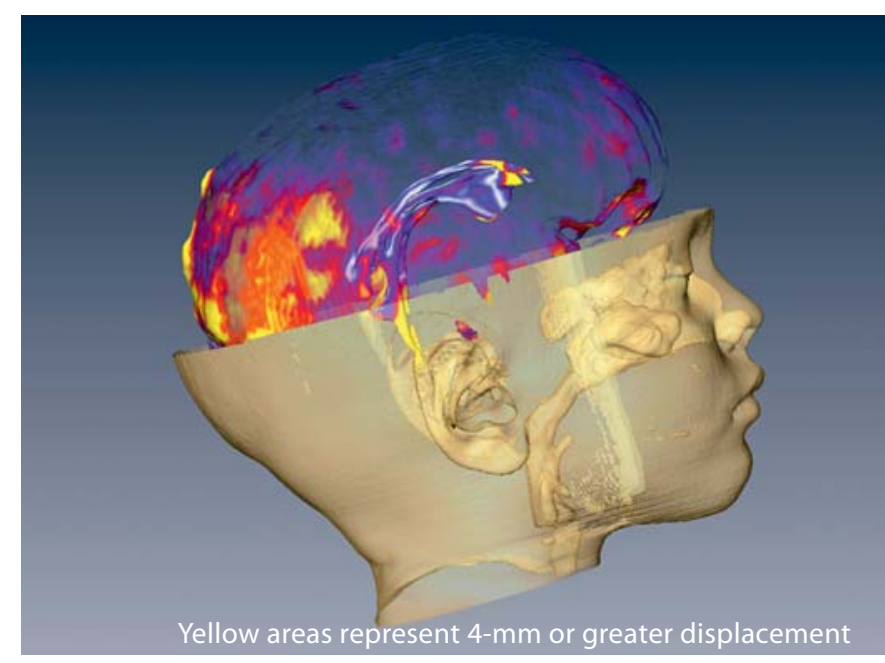

Fig. 9. Translucent color map demonstrating intracranial volume changes with volume changes also shown for the ventricle in situ (also color mapped). Color refers to the online version only.

\section{Discussion}

\section{Distraction Technique Advantages}

The data presented indicate that cranial vault expansion by asymmetric distraction consistently increases intracranial volume and that it can be accurately measured. It also shows that there is a small but measurable increase in the volume of the ventricular system in each patient after cranial vault expansion by distraction.

Treatment for patients 3 years of age and older with craniosynostosis and symptomatic cephalocranial disproportion becomes increasingly difficult as the bones are no longer readily pliable. Published techniques, e.g. the 'FLAG' [6] procedure for sagittal synostosis in infants, are not applicable for that reason. Children in this older group also fail to reliably ossify large full-thickness calvarial defects. This prompted the design of a distraction technique application which reliably stimulates bone formation in areas controlled by the technique design. Transverse asymmetric distraction also maintains dural contact with the overlying bones by utilizing a gradual distraction process. The slow progressive expansion maintains blood supply to the bones being distracted and creates minimal 'dead space' [5]. The slow progressive movement is also the key to stimulating osteogenesis to fill the calvarial defects created.

\section{PET Scan Analysis}

David et al. [7] demonstrated that all patients in their series with single-suture craniosynostosis have regional cerebral metabolic derangement demonstrated by PET scan. These disturbances localized to the occipital cortex. Regional perfusion and metabolic function were improved in all cases after traditional cranial vault remodeling and expansion. This is consistent with findings of visuospatial impairment in children with craniosynostosis and subsequent improvement after cranial vault remodeling [8]. The PET scans indicate that chronically deficient intracranial volume appears to result in reduction of cerebral blood flow. Symptoms of chronic headache and learning disability seen in our patients with cephalocranial disproportion may originate from decreased parenchymal perfusion.

Only a fraction of children with single-suture craniosynostosis have elevated ICP [9]. Despite this, all of Dr. Argenta's patients demonstrated correction of metabolic derangement after cranial vault expansion. ICP cannot be solely relied on to assess the adequacy of intracranial volume or cerebral blood flow. It appears from this study that there is a therapeutic role for cranial vault remodeling in patients with symptomatic cephalocranial disproportion that do not have elevated ICP.

\section{Intracranial Volume Impact on Cerebral Perfusion}

The Monro-Kellie doctrine describes the volumepressure relationship that exists intracranially $[10,11]$. The doctrine proposed that the intracranial compartment is a closed space containing three discrete components. These are brain parenchyma, vascular supply, and the ventricles. Volume change in one of the components must be accommodated by an inverse change in the other two. The brain parenchyma occupies $8 \%$ of the intracranial space, while the blood and cerebrospinal fluid (CSF) each occupy $10 \%$.

The adult cranial contents can only compensate for approximately $100 \mathrm{ml}$ of volume restriction or mass effect prior to decompensation of function. Beyond this threshold, minimal additional intracranial volume decreases in the space normally available for brain parenchyma result in logarithmic increases in ICP. Acute significant elevations of ICP result in gross parenchymal dysfunction, tonsillar herniation and ultimately death. The average volume change in these pediatric patients after transverse asymmetric distraction osteogenesis was $57.46 \mathrm{ml}$.

The intracranial compartment contains a capacitance system to accommodate changes in intracranial volume while maintaining homeostatic ICP. This system is composed of the ventricular system and the dural venous system. The ventricles are in continuity with the subarachnoid space surrounding the spinal cord and can shunt CSF to the spinal column where a distensible reservoir 
Fig. 10. Color map showing another patient. Preferential expansion identified in the posterior parietal areas. Color refers to the online version only.

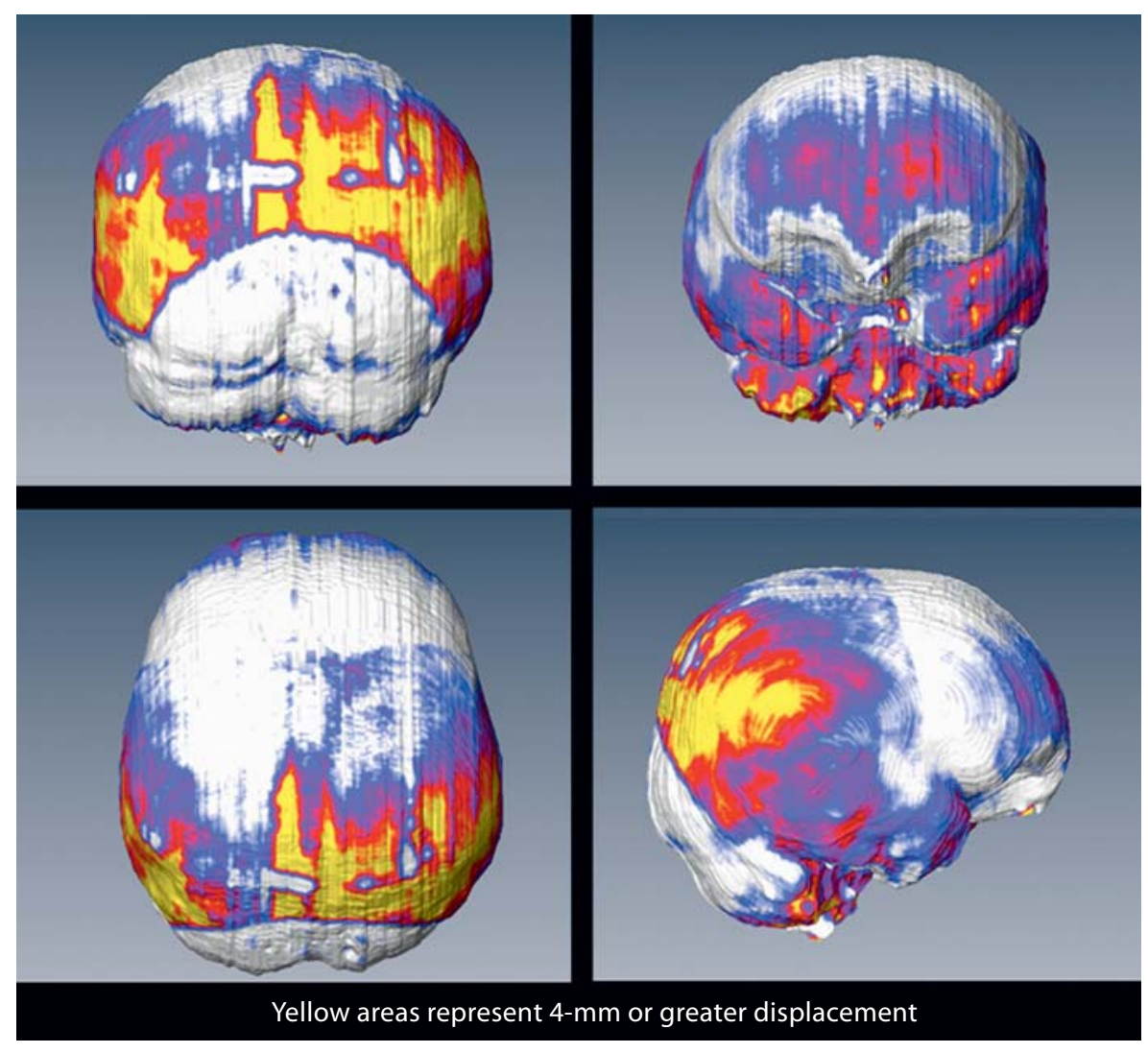

exists. As the intracranial volume becomes increasingly deficient relative to its contents, CSF is shunted out of the ventricles to fill the subarachnoid space around the spinal cord. It is estimated that $70 \%$ of intracranial volume capacitance is provided by the ventricular system. Our measurements show this volume to be approximately 25 $\mathrm{ml}$. The vascular system can provide the remaining $30 \%$ of capacitance but does so with increasing risk of physiologic consequences.

\section{Pediatric Intracranial Capacitance}

In a normal pediatric skull with functioning sutures, compliance within the intracranial compartment is high. As the brain grows, the sutures in the calvarium respond by allowing expansion to produce more intracranial volume. Capacitance from the ventricles is not utilized. Growth restriction from premature sutural fusion causes redistribution of CSF to maintain perfusion and progressively decreases the remaining capacitance of the ventricular system. Once the capacitance of the ventricles and vascular system is exceeded, minimal additional restriction in intracranial volume results in rapidly rising ICP [12].

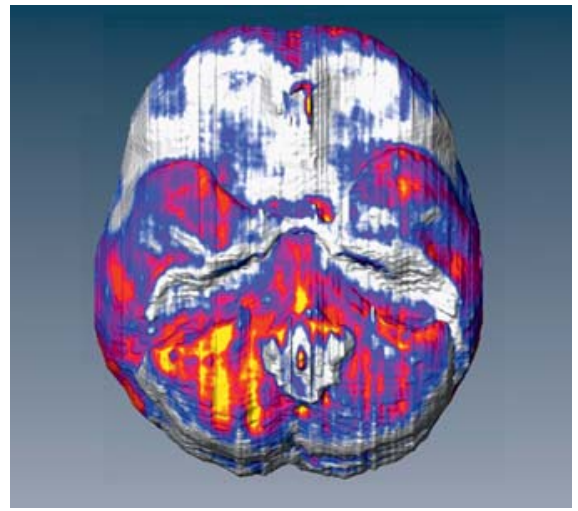

Fig. 11. Unexpected distant effect of cranial vault distraction on skull base.

The perfusion control mechanisms of the intracranial vascular compartment in response to decreased intracranial space are not completely understood. The majority of intracranial blood volume is found on the venous side of the system. The venous component is the most responsive capacitor within the skull and preferentially uses its available capacitance before the ventricular system. The 
dural sinuses progressively flatten in response to growth restriction. This occurs prior to major shifts in CSF.

Normal cerebral blood flow ranges between 45 and 50 $\mathrm{ml} / 100 \mathrm{~g} / \mathrm{min}$ of brain tissue and is directly proportional to metabolic demand. Arterioles vasoconstrict in response to elevated cerebral perfusion pressure and vasodilate in response to decreases in cerebral perfusion pressure. This is the mechanism by which cerebral blood flow is maintained across a range of cerebral perfusion pressures. The basic equation expressing cerebral blood flow is $\mathrm{CBF}=$ $\mathrm{CPP} / \mathrm{CVR}$ (cerebral blood flow is equal to cerebral perfusion pressure divided by the cerebral vascular resistance). Cerebral vascular resistance decreases in response to decreases in cerebral perfusion pressure to maintain cerebral blood flow. Oxygen and glucose delivery is maintained by higher volumes of blood flowing at a slower rate. However, in the presence of inadequate intracranial volume, the cerebral vascular resistance will be increased thus decreasing cerebral blood flow. When the normal physiologic limits are exceeded, degradation of brain function is the result.

Intracranial capacitance is a necessary function of the ventricle. The ventricles serve as a safeguard to prevent critical pressure, and associated decreases in cerebral blood flow within the intracranial space. The ventricles increased in size following cranial vault distraction in all cases in our series. This supports the diagnosis of cephalocranial disproportion and may indicate that a nonphysiologic state is occurring.

When sufficient growth restriction exists to affect the size of the ventricle, vascular alterations have already occurred. It appears that elevated ICP is a late finding which occurs only after prolonged and progressive degradation of normal physiologic brain function. This is the likely etiology of reported symptoms associated with cephalocranial disproportion.

\section{Conclusion}

Quantitative analysis of cranial vault expansion by distraction shows a reproducible increase in total intracranial volume, as well as ventricular, and nonventricular volume. The ventricles expanded in all cases supporting the diagnosis of cephalocranial disproportion and the assumption that compensatory mechanisms have been activated in these patients. ICP in measured patients dropped to normal after cranial vault expansion by internal distraction osteogenesis. Significant abnormal optic disk changes have resolved within weeks and have remained normal for over 5 years. Symptomatic cephalocranial disproportion may exist in the absence of increased ICP. All distracted patients report sustained improvement in symptoms. Expansion of insufficient intracranial volume should have positive implications for cerebral perfusion and function in the developing brain.

\section{Disclosure Statement}

Arlen Denny, MD, FACS is a consultant for Stryker Corp. He does not receive any royalties or other consideration for products referenced in this article.

\section{References}

1 Ilizarov GA, Soǔbel'man LM: Clinical and experimental data on bloodless lengthening of lower extremities (in Russian). Eksp Khir Anesteziol 1969;14:27-32.

-2 Snyder CC, Levine GA, Swanson HM, Browne EZ: Mandibular lengthening by gradual distraction: a preliminary report. Plast Reconstr Surg 1973;51:506.

3 Michieli S, Miotti B: Lengthening of mandibular body by gradual surgical orthodontic distraction. J Oral Surg 1977;35:187.

4 Karp NS, Thorne CHM, McCarthy JG, Sissons HA: Bone lengthening in the craniofacial skeleton. Ann Plast Surg 1990;24:231.

$\checkmark 5$ Lao WW, Denny AD: Internal distraction osteogenesis to correct symptomatic cephalocranial disproportion. Plast Reconstr Surg 2010;126:1677-1688.
6 Amm CA, Denny AD: Correction of sagittal synostosis using foreshortening and lateral expansion of the cranium activated by gravity: surgical technique and postoperative evolution. Plast Reconstr Surg 2005;116: 723-735.

7 David LR, Genecov DG, Camastra AA, Wilson JA, Argenta LC: Positron emission tomography studies confirm the need for early surgical intervention in patients with singlesuture craniosynostosis. J Craniofac Surg 1999; 10:38-42.

8 Kapp-Simon KA, Speltz ML, Cunningham ML, Patel PK, Tornita T: Neurodevelopment of children with single suture craniosynostosis: a review. Childs Nerv Syst 2007;23: 269-281.
-9 Arnaud E, Renier D, Marchac D: Prognosis for mental function in scaphocephaly. J Neurosurg 1985;83:476-479.

10 Monro A: Observations on the Structure and Function of the Nervous System. Edinburgh, Creech \& Johnson, 1823, p 5.

11 Kellie G: An account of the appearances observed in the dissection of two of the three individuals presumed to have perished in the storm of the $3 \mathrm{rd}$, and whose bodies were discovered in the vicinity of Leith on the morning of the 4th November 1821 with some reflections on the pathology of the brain. Trans Med Chir Soc Edinburgh 1824;1:84-169.

$\checkmark 12$ Ryder HW, Epsey FP, Kimbell FD, et al: The mechanism of the change in cerebrospinal fluid pressure following an induced change in the volume of the fluid space. J Lab Clin Med 1953;41:428-435. 